\title{
A PHASED LOGIC MODEL APPROACH TO PUBLIC INVOLVEMENT PERFORMANCE MEASUREMENT
}

\author{
Greg P. Griffin (Corresponding Author) \\ Texas A\&M Transportation Institute \\ The University of Texas at Austin, Community and Regional Planning \\ 505 East Huntland Drive, Ste. 455, Austin, TX 78752-3717 \\ Tel: (512) 407-1111; Email: g-griffin@tti.tamu.edu
}

Alexandra R. Radtke

Texas A\&M Transportation Institute

505 East Huntland Drive, Ste. 455, Austin, TX 78752-3717

Tel: (512) 467-0946; Email: alexrradtke@gmail.com

\section{Madison Metsker-Galarza}

Texas A\&M Transportation Institute

3135 TAMU, College Station, TX 77843-3135

Tel: (979) 862-1678; Email: m-metsker-galarza@tti.tamu.edu

\section{Gretchen Stoeltje}

Texas A\&M Transportation Institute

505 East Huntland Drive, Ste. 455, Austin, TX 78752-3717

Tel: 512-407-1165; Email: g-stoeltje@tti.tamu.edu

\section{Tina Geiselbrecht}

Texas A\&M Transportation Institute

505 East Huntland Drive, Ste. 455, Austin, TX 78752-3717

Tel: 512-407-1116; Email: t-geiselbrecht@tamu.edu

\section{Ben Ettelman}

Texas A\&M Transportation Institute

505 East Huntland Drive, Ste. 455, Austin, TX 78752-3717

Tel: 512-407-1166; Email: b-ettelman@tti.tamu.edu

\section{Chris Simek}

Texas A\&M Transportation Institute

505 East Huntland Drive, Ste. 455, Austin, TX 78752-3717

Tel: (512)407-1153; Email: c-simek@tti.tamu.edu

Paper number 18-00053

Word count: 5,9111 words text +1 table and 4 figures x 250 words (each) $=7,161$ words

Revised submission November 15, 2017, for presentation at the $97^{\text {th }}$ Annual Meeting of the

45 Transportation Research Board, and consideration for Transportation Research Record. 


\begin{abstract}
Performance measurement is a key method for evaluating and improving services in transportation, yet few agencies have systematically evaluated public participation in transportation planning. Review of previous studies reveals that measures of effectiveness and techniques for evaluation vary widely, and often provide cursory reporting of the immediate outputs of involvement efforts, rather than system outcomes related to public participation. Interviews and government documents from three detailed cases in the United States transportation planning suggest that complexity, perceived subjectivity and an extended period of project development creates challenges for performance measurement of public participation. To demonstrate use of the logic model approach for evaluation of public participation, the research team performed three case studies that separate broad phases of projects into context, implementation, and results. This phased approach supports the identification of performance measures that may address immediate outputs of a public participation process, in addition to intermediate and later outcomes related to public participation. Results from the multiple case studies suggest that performance measures are more likely to be sustained and impactful when devised for simplicity, supported by an agency champion, and resources are in place for institutionalization of the process as part of agency operations. The logic model approach clarifies that performance targets should be tailored by an organization to address a particular phase of the project development process.
\end{abstract}

Keywords: public participation, performance measurement, logic modeling; multiple case study 


\section{INTRODUCTION}

In recent years, public scrutiny and accountability for public agency performance and spending has steadily increased. Methods of accessing and disseminating information are more available than ever. At the same time, agencies are experiencing ongoing budgetary constraints while demand for public services is increasing. In this context, it has become increasingly important for government agencies to be transparent in how they meet public needs. Currently, performance measurements are commonly required for transportation investment and operations. However, the planning process and products, including public participation, play an important role in aligning transportation priorities with public needs.

Public participation is required for all phases of transportation decision-making, yet little guidance is available on how to monitor the impacts of these efforts. The United States' Fixing America's Surface Transportation, or "FAST Act" requires transportation agencies to monitor a broad range of performance metrics, but specific public involvement measures are not currently required at the federal or state level (1). The phased logic model presented in this research focuses on public involvement in transportation during the planning phase because this is the primary focus for the practice of public engagement. However, researchers and practitioners would benefit from additional research to test the model at other stages of the project life cycle.

Cognizant of the current framing and challenges for public participation in contemporary transportation planning, the objective of this study is to: develop a method for applying a logic model to guide performance measurement for public involvement through multiple case studies. TTI researchers reviewed existing research on performance measurement of public participation in transportation, conducted interviews with staff from a wide range of transportation agencies, and reviewed documents that show how they deployed performance measurement in this context - and their challenges. This research frames findings using logic modeling - a relatively simple mechanism to clarify and illustrate both concepts and programs. Through analysis of extensive case study materials, this study demonstrates how logic modeling, deployed in a program evaluation mode, can facilitate stronger insights for both practitioners and researchers, resulting in improvements to the practice and study of public participation in transportation planning.

The next section of this paper summarizes the literature on performance measurement for public involvement, and the application of logic modeling for program evaluation. Case study data and qualitative methods are presented next. Three cases of public involvement in transportation planning deploy logic models as examples to show how the process can clarify meaningful performance measures. This paper concludes with a summary of the findings from the cases, and lessons for both designing and evaluating public involvement for transportation planning with performance measurement.

\section{LITERATURE REVIEW}

\section{Performance Measurement for Public Involvement}

To evaluate performance measurement, two separate categories of public participation measures, as seen in the paper, need to be defined. Outputs are the measurable actions of the public involvement process, such as the number of events held, or comments received. Outputs tend to be directly measurable and can include both the "quantity and quality of a service" (2). Outcomes seek to measure impacts to the process or policy as a result of public involvement. These may include changes to a draft plan, or differences in how participants work with the agency. Outcomes tend to be more qualitative and may require analysis over some time to measure change. Though few agencies consistently measure both outputs and outcomes of public participation, doing so makes it possible to gain insight into the ability of public involvement activities to meet agency goals.

Most evaluation methods are centered on criteria that are straightforward to tabulate and evaluate. The direct outputs of public participation processes often center on quantifiable characteristics of involvement, including the number of engagement opportunities, counts of attendees, and documented comments received from participants $(3,4)$. Increasingly, online public engagement platforms build evaluation components into their design, fostering real-time assessment and improvement (5-7). Comparison of demographics and geography of process participants with the larger community can reveal 
meaningful differences and highlight injustices $(3,8)$. Earlier research by TTI identified four principles for successful public engagement: accessible events, engaging interactions, multi-platform strategies, and an outcome-oriented process, and tied measurable actions to these principles (9). Multi-platform strategies offer opportunities for the public to engage in a number of different formats, providing convenience to the public.

To measure the effectiveness of public engagement, research suggests five key criteria are needed: process quality, inclusion, clarity, and utility of decision support, and efficiency (24). These criteria can be assessed across the various techniques in a participation process, considering what can go right and wrong during implementation (10). Two key areas of evaluation which have been under-emphasized in recent transportation engagement research, with rare exceptions $(11,12)$, include "accountability by tracking shifts in public preferences," and "enhancing two-way communication by requiring a dialogic approach to problem understanding and solution development" (13). These issues align with outcomes that require evaluation over a longer term than a typical project cycle affords, preventing a crucial gauge of participant empowerment $(14,15)$.

The academic and industry-specific literature agree that both immediate outputs of planning processes, and longer-term outcomes, need to be assessed to understand the impact of public participation on transportation. The most comprehensive guide in this regard, to date, is "Performance Measures to Evaluate the Effectiveness of Public Involvement Activities in Florida" (16). This approach addresses the components of involvement that are readily quantified and assessed over time and those for which agencies have the most direct control..

Contrasting with frameworks for analyzing public participation outputs and outcomes, some focus on process, such as a three-phase approach of stimulating public interest, targeting community groups, and customizing outreach messaging (17). Other recent evaluations have emphasized the role of communication technologies, particularly social media, to accomplish parallel goals of public information and plan input by the public $(12,18-20)$. In all cases, agency staff work through mandates and strategic decisions in the planning process that affect likely outcomes from public processes (21). Findings from these contributions differ. The present study aims to provide a broader approach to aligning project phases to logical measures. .

\section{Challenges for Performance Measurement}

Gaps between current practice and truly effective implementation of public participation performance measurement exist. The causes of the gaps are varied and may run the gamut from lack of support at agency leadership, manifest by low prioritization and inadequate resource allocation, to training and support for staff charged with implementing successful public involvement. The challenges to closing these gaps include agency leadership support at the highest levels, a commitment to evaluation, consistency in evaluation methods and the resources to do the job.

Time and staffing issues are important restrictions to consistent performance measurement of public participation (22-24). When designing public processes, staff work to balance the perceived preferences of the public, and how practical a given comment may be (25). Performance measurement adds additional demands on staff that do not directly support the immediate demands of the project. Though many may see the value of systematic performance evaluation, lack of focused support through staff time, training, funding, or a mandate is a persistent challenge.

Inconsistency in how the performance measures are applied poses another challenge. Though some resources in this review emphasize the need for flexibility of measures that address a project's unique goals (26), there is also value in adding consistency through standard key measures (16). Changing performance measures for each project prevents evaluation of trends over time, or identification of variables that may lead to an increase or decrease in a given measure. Consistent measures are also related to time and staffing - it takes resources to standardize the practice, but doing so supports continuous improvement (27).

\section{Logic Modeling for Program Evaluation}

Evaluating public engagement efforts can be a complex process. Diagramming processes as a visual logic model arranges concepts and actions with practical consequences to aid understanding. For instance, a logic 
model was employed in the Atlanta BeltLine project to help illustrate "the Beltlines' potential direct and indirect effects in five dimensions such as access and physical activity - each having a bearing on potential health outcomes" (28). Logic modeling clarifies both the thinking of transportation staff, and provides a visualization to convey ideas and intents to others (29).

This study breaks public participation processes into context, implementation, and results, enabling a clearer description of the key factors in how the processes work, and helps delineate separate issues as measurable components, as shown in Figure 1. In this paper, context includes all of the factors that affect how a transportation organization carries out public participation, including both internal and external influences and resources (30). Agency staff, consultants, operating budget, changing politics, and other factors relate to either the influences or resources afforded by a transportation agency for public participation and as such provide context. Implementation includes the participation activities (such as public meetings and social media), and the direct outputs, such as attendance, comments, or online 'likes,' and similar. Results include anything affected by the implementation of public participation. Short-term outcomes can include agency responses to comments or questions, such as alteration of a roadway plan or addition of a project meeting or review. Intermediate outcomes could include funding decisions and construction of the altered roadway. Impacts could be the downstream results of the project such as measures of collision rates on a roadway, or capacity in terms of people per hour, for example. Typical evaluations of public participation include measuring outputs from activities while ignoring both the context and longer-term outcomes of the effort.

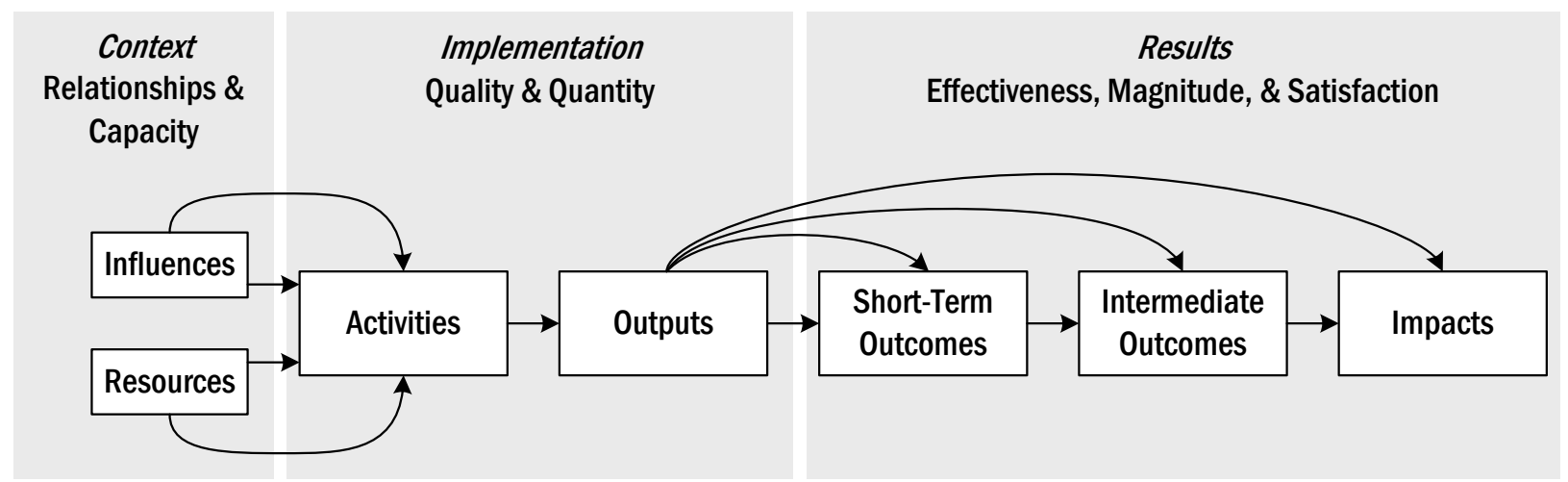

\section{FIGURE 1 Program evaluation logic model $(30,31)$}

Evaluation of public participation using logic modeling requires some forethought and planning to implement, but Knowlton and Phillips provide clear steps to develop a logic model for a program, such as public participation in transportation planning (31). First, analysts should consider how transportation decision-makers would use the logic model to improve processes. Working from right to left in the diagram in Figure 1, an analyst identifies measurable outcomes linked to activities and associated outcomes. Observable outputs logically associate with specific actions - clarifying these forms the basis of evaluating quality and quantity of implementation. Contextual issues including available resources and human influences may have either a direct or an indirect role in the process. Logic modeling separates and clarifies the interaction between processes and products, and provides a guiding framework for evaluating public involvement used in this study.

\section{DATA AND METHODS}

This study employs a multiple case study approach, which balances context-specific detail of actual transportation projects, with the generalizability of different types of agencies and communities (32-34). Transportation agency documents and interviews form the core material for this study. This approach supports triangulation of findings, by cross-verifying published reports with anonymous interviewee responses, and then corroboration between researchers' preliminary assessments.

Researchers identified six transportation planning case studies for this topic using three criteria. 
First, the cases had to have documented efforts to evaluate public participation, ensuring at least a minimal amount of information about the case's context and results were available online. Second, researchers sought a balance of regional and state transportation agencies, recognizing that the resources and context of a state department of transportation and a metropolitan planning organization vary widely. Third, researchers chose cases with broad geographic representation to improve generalizability across cultural and political environments (35). This paper documents three final case studies that best reflected these criteria.

After gathering preliminary resources, such as public participation plans and evaluation reports, researchers identified interviewees through either the documents' contact information or contacting agency staff to determine a current public involvement staff contact. Researchers conducted interviews by telephone with agency staff, taking approximately one hour each. One researcher followed a semistructured interview script with prompts relating to public involvement, performance measurement, and agency practices, while a second researcher took notes during the conversation. Researchers emailed respondents to obtain and clarify additional documentation on the cases. After the initial draft of findings, researchers asked an interviewee from each agency to assess the interim work-a qualitative research process of member checking to improve validity (36).

\section{TABLE 1 Summary of Case Data Sources Used in this Study}

\begin{tabular}{lllccc}
\hline \multicolumn{1}{c}{ Cases } & State & Project Phase & Interviewees & $\begin{array}{c}\text { Agency } \\
\text { Reports }\end{array}$ & $\begin{array}{c}\text { Additional } \\
\text { Materials* }\end{array}$ \\
\hline $\begin{array}{l}\text { State Route 600 } \\
\text { Widening }\end{array}$ & Florida & $\begin{array}{l}\text { Preliminary } \\
\text { Design }\end{array}$ & 2 & 3 & 3 \\
$\begin{array}{l}\text { Statewide Long Range } \\
\text { Transportation Plan }\end{array}$ & Tennessee & Planning & 3 & 5 & 4 \\
Plan Bay Area & California & Planning & 2 & 4 & 2 \\
\hline Total & & & 7 & 12 & 9 \\
\hline
\end{tabular}

* Additional materials included unpublished reports, emails, and websites referred by interviewees.

Note: Researchers conducted three other case studies with interviews and document, but these are omitted from this paper for brevity.

\section{The Phased Logic Model Approach}

A phased logic model approach is proposed to facilitate evaluation of public participation activities over the project development lifecycle. The context, implementation, and results of a public participation process are theorized to align with transportation planning factors, critical inputs, and feedback, as described in the Federal Highway Administration's description of the transportation planning process (37). These are the broad "phases" of this approach to logic modeling - the context, implementation, and results occur sequentially, supporting three distinct opportunities to understand public participation.

First, the context of a given public involvement process can include the internal structures and resources of a transportation agency, the societal and local community issues and concerns, and the resources available for implementing public participation. Second, an implementation phase includes the actions taken by the transportation agency, including the immediate outputs of their work, such as the number of people attending public meetings. Third, the phased logic model addresses outcomes of the public participation process. Short-term outcomes might include the comments dealt with in subsequent plans, and the networking that occurs between constituent groups, the transportation agency, and individuals brought into the process. Longer-term outcomes could include changes in project implementation, such as routing or design changes, which may culminate in community impacts, which would require postimplementation assessment. When viewed along the project development lifecycle, performance measures can be tailored to precisely inform the applicable phase of the project — whether it is immediate feedback on public involvement or more long-term impacts that could require additional resources. 


\section{State Route 600 (John Young Parkway) Widening}

The Florida Department of Transportation (FDOT) identified a need to add an additional lane in each direction to a section of SR 600 (John Young Parkway), south of downtown Kissimmee, Florida. The project goals were to "improve the traffic capacity and enhance highway safety and mobility" (38). The project was proposed to convert existing median space for added capacity, with a proposed typical section including six, 11-foot $(3.3 \mathrm{~m})$ wide lanes, a 22 -foot $(6.7 \mathrm{~m})$ median, 7 -foot $(2.1 \mathrm{~m})$ bike lanes and 5 -foot $(1.5 \mathrm{~m})$ sidewalks in each direction (39). The majority of the public involvement for this project took place in 2015 and 2016., An open house and public hearing were held in October 2016 in downtown Kissimmee.

FDOT had recently developed a Public Involvement Performance Measurement (PIPM) system in partnership with University of South Florida's Center for Urban Transportation Research (CUTR), which developed "a systematic methodology to evaluate the effectiveness of public involvement processes and practices based on defined performance measures" (16). FDOT and the project consultants used the new PIPM system, along with other FDOT guidance on public involvement, to guide development and evaluation of the public participation process in the John Young Parkway project.

After the public meeting, the John Young Parkway team sent follow-up surveys to local residents and businesses in the area, finding that some people did not feel they were adequately notified, or the meeting was inconveniently timed, preventing some from participating directly. Mailed responses to the follow-up survey revealed challenges not revealed by in-person comments, suggesting a role for including evaluations that do not require face-to-face interaction. However, results from analysis of documents and an interview with staff indicate that the practice is not yet institutionalized at FDOT, even though the agency has developed a robust system for measuring public involvement. Figure 2 is a logic model summarizing performance measurement for public participation in the John Young Parkway widening project, showing the progress of the project context, how performance measures were implemented, and the immediate outcomes. Intermediate outcomes have not yet been assessed, and similarly, the long-term impacts would require follow-up during and after completion of the project. In summary, the John Young Parkway case materials demonstrate an initial phase of outcome assessment of public participation with recommendations to improve participation, but additional work is needed to gain further knowledge from this project.

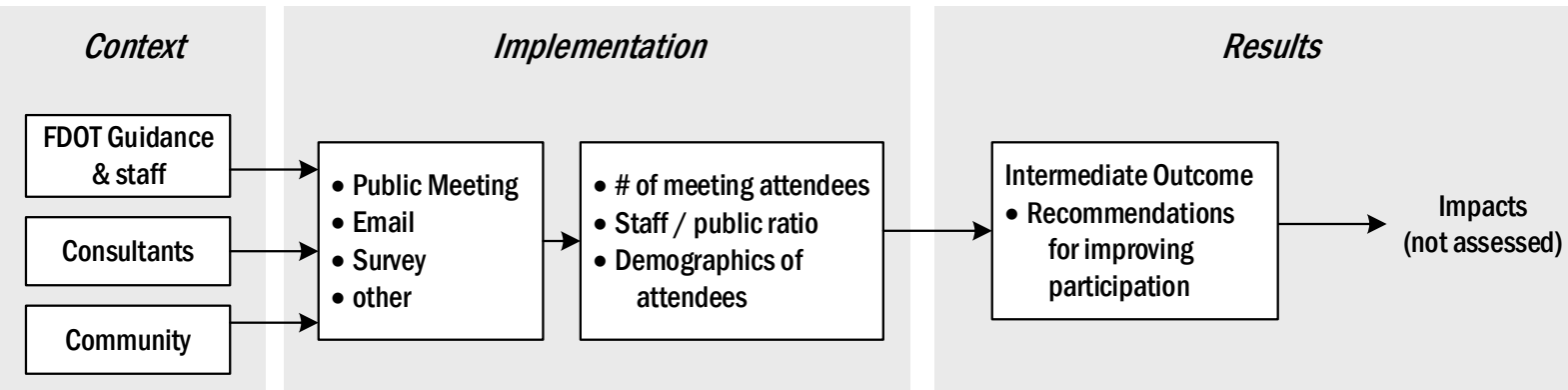

\section{FIGURE 2 SR 600 Widening Public Involvement Performance Measurement Logic Model}

\section{Statewide Long Range Transportation Plan}

From 2013 to 2015, the Tennessee Department of Transportation (TDOT) led an update of the state's 25year Long Range Transportation Plan. In 2012, the state had adopted a Public Involvement Plan with detailed guidelines for public outreach and the collection of simple quantitative measures of public participation in federally-funded transportation planning processes (40). This plan provided TDOT with a framework for its public involvement strategy during the Long Range Transportation Plan update.

TDOT's Public Involvement Summary for the Long Range Transportation Plan provides a detailed account of the different methods used to reach the public throughout the process (41). The first phase of outreach focused on informing the public about the importance of the 25-year plan, and the second phase emphasized collecting input about the draft plan. During Phase 1, TDOT cultivated interest around 
the plan update by reaching out to a diverse network of public and private sector participants. A central website directed people to information and access to the process with links to request informational meetings called "book-a-planner" and online surveying (42). Regional summits served as a means of gathering stakeholders together for discussion and collecting input. In the second phase, the team added focus groups, a digital mapping platform for registering geo-located suggestions, an additional online survey, and a postal mailing targeted input from underserved populations.

Quantitative outputs from TDOT's robust public involvement strategy are noteworthy, with over 4,000 online surveys completed, over 5,000 event participants and over 6,000 visits to the website. However, there is minimal connection shown between output and outcomes during and after the process. There are brief mentions of incorporating input from Phase 1 into Phase 2 proceedings, but how the agency used input and molded Phase 2 is not detailed.

An interview with staff revealed that the public involvement priorities of the agency have shifted over time (43). Though the Statewide Long Range Transportation Plan was completed, resources for evaluating outcomes also concluded. Public involvement staff work on different projects, and further assessment of intermediate outcomes or impacts would require additional resources. Illustrated as a logic model in Figure 2, this project's outreach and assessment achieved a great deal through implementation, but outcomes are not yet assessed.

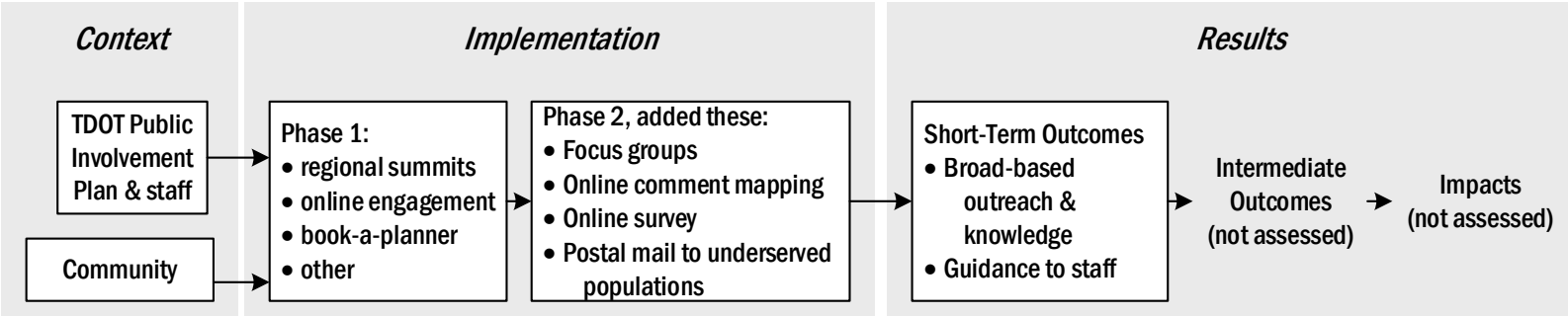

\section{FIGURE 3 Tennessee Long Range Transportation Plan Public Engagement Logic Model}

\section{Plan Bay Area Public Outreach and Participation Program}

Plan Bay Area is the San Francisco region's long-range integrated transportation and land-use plan, developed by the Metropolitan Planning Commission (MTC). The agency's Public Participation Plan, developed in 2010, guided engagement for the plan, and included six key areas of evaluation: diversity, reach, accessibility, impact, education and participant satisfaction. The public participation plan includes both quantitative and qualitative metrics to measure performance of public participation. For example, the area of diversity targets a "representative cross section," while one of the reach targets is " 6,000 individuals participate via survey and meeting attendance". Likewise, the areas may be evaluated in terms of outputs (diversity, reach accessibility) and outcomes (impact, education and participant satisfaction). After the Plan Bay Area public process was completed, MTC took the extra step to engage a consultant to evaluate the agency's outreach program, providing an external review and detailed report that includes performance measures (44). The report described how the agency met its targets for the accessibility and impact measures, assessed quantitatively. Though education and participant satisfaction measures were quantifiable through the survey, the report only evaluated these metrics subjectively. Inconsistent use of the performance measures undermined the effort of creating both the evaluation method and the effort to independently evaluate the process and publish results.

Interviews with staff revealed challenges with measuring change over time, and with implementing quantitative performance measures. When asked whether the agency compares findings year over year, staff described that they "generally don't, rather we just evaluate the public involvement for each plan." (personal communication, April 5, 2017). Staff also noted that changing contexts makes it hard to compare involvement activities over time, citing dramatically different levels of public interest between the previous plan and the current one. The challenge of tracking quantitative outputs such as meeting attendance or number of comments is that the level of interest in a given outreach effort may vary for reasons entirely separate from staff"s work. Staff reported "there is a lot less interest for the plan we are currently working 
on because it is an update. It does not generate the level of interest the original March 2017 plan did. In addition, we were targeted by conservative groups opposed to regional planning during our first plan, so there was a ton of interest, both from the progressive side and from the more conservative side, like those from Tea Party" (personal communication, April 5, 2017). Tracking quantitative outputs from public participation efforts may support the description of the process, but evaluation of the outcomes - both the short-term impacts to the plan and longer-term changes to the transportation system resulting from the public process - is missing from these cases to date.

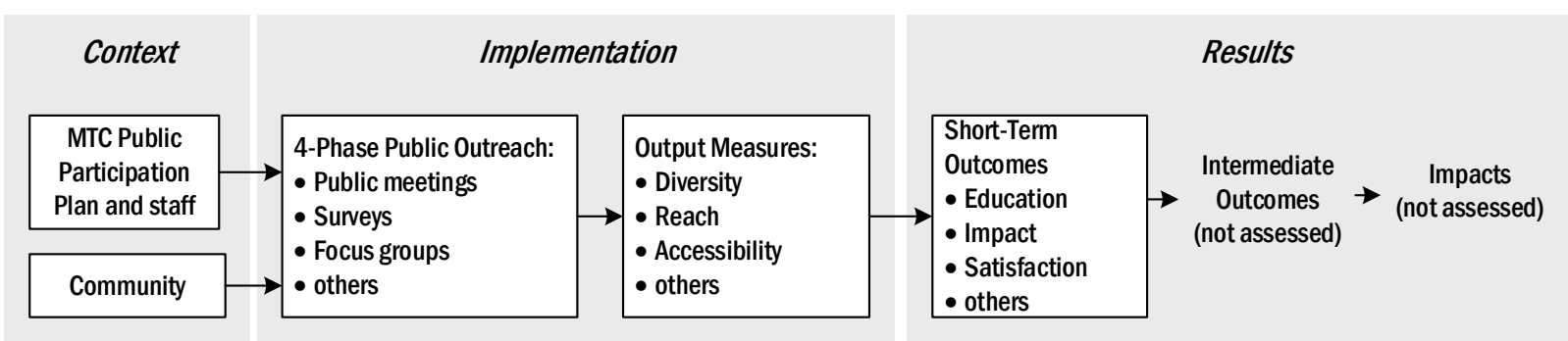

\section{FIGURE 4 Plan Bay Area Public Outreach and Engagement Logic Model}

\section{Validity and Reliability}

The strength of the multiple case method in this study is that the data used in the study-agency reports, interviews, and follow-up materials obtained by researchers-are grounded in the context of the organizations involving the public in transportation planning. Singleton and Straights describe convergent validity as the "correspondence of results when a concept is measured in different ways" (45). By beginning with project materials, proceeding to internal assessments by agency staff, and then reflecting on the results within the research team, findings in this study are consistent between triangulated sources. Returning to our informants via member checking - asking an interviewee from each agency to review our initial findings - resulted in additional detail, but not changes in key findings. In addition, United States regulations support some consistency in how agencies implement transportation planning, despite changes in organizational and cultural contexts. The reliability of findings in these cases suggest some of the lessons are likely transferable to similar contexts.

Each of these cases incorporated and publicized evaluation of immediate outcomes of the planning process, but none conducted a review of outcomes related to impacts to the transportation system or communities. This finding is consistent with previous evaluations of public planning processes $(4,26,27$, $46,47)$, yet the logic model suggests future evaluations could improve upon these findings by focusing on the results of planning processes, rather than the direct outputs of process implementation. Furthermore, additional methods capable of reviewing a larger number of public participation cases, such as surveying or data mining, are needed to further evaluate the reliability of findings in this article $(18,48)$.

\section{CONCLUSIONS}

Following a review of the case materials and interviews with three transportation agencies, several lessons may apply to the future development of public involvement efforts. Overall, the evidence suggests that systematic evaluation of public participation efforts is a challenge, given other agency priorities. However, three suggestions for continuing the practice include simplification, championing, and institutionalization.

Simple measures are more likely to be repeated. The SR600 case in Florida demonstrates clear implementation of public involvement performance measures, as defined in the PIPM system, but institutionalization and replicability remain challenges. Despite a solid foundation in research and a flexible implementation process, individual districts were unlikely to prioritize this effort, due to staffing and resource limitations, without a mandate from leadership. High-level support of simple performance measures, through either internal culture or external mandate, is more likely to result in consistent implementation.

Champions play a role in developing and implementing performance measures. Though not 
mentioned directly, elected officials, professional associations, agency leaders, and staff can serve as champions for performance measurement. A single staff member led much of Florida's public participation performance measurement over the course of several years, and yet the agency has not fully integrated the work across divisions. One person can provide the motivation to begin effective evaluation programs but there must be buy-in from leadership to perpetuate the program. MTC's performance measures were the result of a top-down vision to create the system, and bottom-up technical skills to report them. One-time evaluations of major projects, such as the Evaluation of the Plan Bay Area Public Outreach and Participation Program (44), can inspire individuals to find the most appropriate performance measures for transportation agencies, which may be repeated with continued community interest and agency leadership. Qualitative case research showed both who led each effort, and how champions struggled to maintain performance measurement of public engagement over time.

Institutionalization - whether by regulation or habit - is often the difference between short-term efforts, and long-term understanding gleaned from precise performance measurement. Perhaps the strongest example from the case studies of institutional support of public involvement activities is California's law requiring public participation, SB 375. That law required MTC's Public Participation Plan, which guides their performance measurement process. Consistent with previous research on public engagement in planning (21), statutory mandates of public participation ensure regular compliance, at the very least. However, mandates tend to not require specific data points, but provide local flexibility to develop appropriate measures. Rather than a one-time effort, institutionalizing performance measurement leverages previous efforts to understand trends over time.

Transportation agencies can understand and manage public participation efforts in public perception, project delivery, and agency costs through systematic performance measurement. Since transportation project development can be protracted over many years, a phased logic model approach can help isolate the context, implementation, and results of a public process. Project phases can align with evaluation phases, ensuring transportation agencies can respond meaningfully to pressures concerning the efficacy of their public participation efforts. However, agencies have to plan for the workload to be part of everyday expectations. Providing clear leadership, simple measures, and institutional resources are likely to support long-term use and benefits of performance measures for public involvement. Future research should explore additional phases of project development beyond the present emphasis on planning, and include longitudinal analysis of outcomes in cases.

\section{ACKNOWLEDGEMENTS}

The authors greatly appreciate the contributions of the agency staff interviewed in this study, in addition to the Transportation Research Board anonymous reviewers. This research was supported in part by the Texas A\&M Transportation Institute Policy Research Center. The first author takes responsibility for any errors or omissions. 


\section{REFERENCES}

2

1. U.S. Department of Transportation. The Fixing America's Surface Transportation Act or "FAST Act." https://www.transportation.gov/fastact. Accessed Apr. 20, 2017.

2. Boyne, G. A. Concepts and Indicators of Local Authority Performance: An Evaluation of the Statutory Frameworks in England and Wales. Public Money and Management, Vol. 22, No. 2, 2002, pp. 17-24.

3. Alter, R., M. Lewiecki, M. Renz-Whitmore, and D. Albright. Accountable Public Involvement: Partnership Approach to Proposed Transportation Project. Transportation Research Record: Journal of the Transportation Research Board, Vol. 2077, 2008, pp. 4653.

4. Lowry, M. B. Online public deliberation for a regional transportation improvement decision. Transportation, Vol. 37, No. 1, 2010, pp. 39-58.

5. Lowry, M. B., T. Nyerges, and G. S. Rutherford. Internet Portal for Participation of Large Groups in Transportation Programming Decisions. Transportation Research Record: Journal of the Transportation Research Board, Vol. 2077, 2008, pp. 156-165.

6. MetroQuest. MnDOT 20-Year State Highway Investment Plan (MnSHIP). http://metroquest.com/portfolio/mndot-20-year-state-highway-investment-plan-mnship/. Accessed Apr. 19, 2015.

7. Stiegler, H., and M. D. T. De Jong. Facilitating personal deliberation online: Immediate effects of two ConsiderIt variations. Computers in Human Behavior, Vol. 51, No. PA, 2015, pp. 461-469.

8. Prevost, D. Geography of Public Participation: Using Geographic Information Systems to Evaluate Public Outreach Program of Transportation Planning Studies. Transportation Research Record: Journal of the Transportation Research Board, Vol. 1981, 2006, pp. 8491.

9. Geiselbrecht, T., B. Fette, T. Lomax, and J. Wagner. Mobility Investment Priorities Project Public Engagement Report. College Station, Texas, 2012.

10. IAP2. Public Participation Toolbox. http:/c.ymcdn.com/sites/www.iap2.org/resource/resmgr/imported/06Dec_Toolbox.pdf. Accessed Sep. 24, 2016.

11. Griffith, R., and B. Young. Using Technology to Build and Manage a Two-Way Public Conversation on Transportation Issues. Transportation Research Record: Journal of the Transportation Research Board, Vol. 2397, 2013, pp. 145-152.

12. Evans-Cowley, J. S., and G. Griffin. Microparticipation with Social Media for Community Engagement in Transportation Planning. Transportation Research Record: Journal of the Transportation Research Board, Vol. 2307, 2012, pp. 90-98.

13. Grossardt, T., K. Bailey, and J. Brumm. Structured Public Involvement: Problems and Prospects for Improvement. Transportation Research Record: Journal of the Transportation Research Board, Vol. 1858, 2003, pp. 59-102.

14. Arnstein, S. R. A Ladder Of Citizen Participation. Journal of the American Institute of Planners, Vol. 35, No. 4, 1969, pp. 216-224.

15. Álvarez Sánchez, D., D. Pardo Gimilio, and J. Isnardo Altamirano. Crowdsourcing: A New Way to Citizen Empowerment. In Advances in Crowdsourcing, Springer International Publishing, Cham, pp. 73-86.

16. Kramer, J., K. Williams, C. Hopes, and A. Bond. Performance Measures to Evaluate the Effectiveness of Public Involvement Activities in Florida. Florida Department of Transportation, Tampa, FL, 2008. 
17. Casello, J. M., W. Towns, J. Bélanger, and S. Kassiedass. Public Engagement in Public Transportation Projects. Transportation Research Record: Journal of the Transportation Research Board, Vol. 2537, 2015, pp. 88-95.

18. Majumdar, S. R. The case of public involvement in transportation planning using social media. Case Studies on Transport Policy, 2016.

19. Bakht, M. N., and T. E. El-Diraby. Hidden Social Networks That Drive Online Public Involvement in Infrastructure Construction Case Study of Light Rail Transit Projects in North America. Transportation Research Record, No. 2453, 2014, pp. 84-93.

20. Camay, S., L. Brown, and M. Makoid. Role of Social Media in Environmental Review Process of National Environmental Policy Act. Transportation Research Record: Journal of the Transportation Research Board, Vol. 2307, 2012, pp. 99-107.

21. Brody, S. D., D. R. Godschalk, and R. J. Burby. Mandating Citizen Participation in Plan Making: Six Strategic Planning Choices. Journal of the American Planning Association, Vol. 69, No. 3, 2003, pp. 245-264.

22. Morris, A., and L. Fragala. Effective public involvement using limited resources. Transportation Research Board, Washington, DC, 2010.

23. Lewis, J., and J. S. Lane. Public Outreach in Pedestrian Plan for Durham, North Carolina: Effectiveness in a Diverse Community. Transportation Research Record: Journal of the Transportation Research Board, Vol. 1994, 2007, pp. 138-146.

24. Nabatchi, T. A Manager's Guide to Evaluating Citizen Participation. Washington, D.C., 2012.

25. Griffin, G. P. Geographic specificity and positionality of public input in transportation: a rural transportation planning case from Central Texas. Urban, Planning and Transport Research, Vol. 2, No. 1, 2014, pp. 407-422.

26. Laurian, L., and M. M. Shaw. Evaluation of Public Participation: The Practices of Certified Planners. Journal of Planning Education and Research, Vol. 28, No. 3, 2008, pp. 293-309.

27. Bailey, K., T. Grossardt, and J. Ripy. High-Performance Public Involvement. Transportation Research Record: Journal of the Transportation Research Board, Vol. 2499, 2015, pp. 45-53.

28. Aimen, D., and A. Morris. NCHRP Report 710 Practical Approaches for Involving Traditionally Underserved Populations in Transportation Decisionmaking. Transportation Research Board of the National Academies, Washington, D.C., 2012.

29. McLaughlin, J. A., and G. B. Jordan. Using Logic Models. In Handbook of Practical Program Evaluation, John Wiley \& Sons, Inc., Hoboken, NJ, USA, pp. 62-87.

30. W.K. Kellogg Foundation. W.K. Kellogg Foundation Logic Model Development Guide. W.K. Kellogg Foundation, Battle Creek, Michigan, 2004.

31. Knowlton, L. W., and C. C. Phillips. The logic model guidebook: Better strategies for great results. SAGE, Los Angeles, 2012.

32. Stephenson, K. L. Can Government Mandate Citizens' Voice?: a case study in transportation policy. The University of Wisconsin-Milwaukee, 2010.

33. Martinson, K., and C. O'Brien. Conducting Case Studies. In Handbook of Practical Program Evaluation, John Wiley \& Sons, Inc., Hoboken, NJ, USA, pp. 177-196.

34. Flyvbjerg, B. Five Misunderstandings About Case-Study Research. Qualitative Inquiry, Vol. 12, No. 2, 2006, pp. 219-245.

35. Bickerstaff, K., R. Tolley, and G. Walker. Transport planning and participation: The rhetoric and realities of public involvement. Journal of Transport Geography, Vol. 10, No. 1, 2002, pp. 61-73. 
36. Goodrick, D., and P. J. Rogers. Qualitative Data Analysis. In Handbook of Practical Program Evaluation, John Wiley \& Sons, Inc., Hoboken, NJ, USA, pp. 561-595.

37. U.S. Department of Transportation. The Transportation Planning Process Briefing Book. Washington D.C., 2015.

38. Zawadski, R. SR 600 (John Young Parkway) Public Assessment Design Memorandum. Ormond Beach, FL, 2011.

39. FDOT Central Florida Roads. 418403-3 SR 600 (US 17/92) from Pleasant Hill Road to Portage Street. http://www.cflroads.com/project/4184033/SR_600_US_17_92_from_Pleasant_Hill_Road_to_Portage_Street. Accessed Jul. 24, 2017.

40. Tennessee Department of Transportation. Public Involvement. https://www.tn.gov/tdot/topic/transportation-plan-public-involvement. Accessed Mar. 28, 2017.

41. Tennessee Department of Transportation. 25-Year Long Range Transportation Policy Plan Public Involvement Plan. Nashville, TN, 2016.

42. Tennessee Department of Transportation. Book-A-Planner. https://www.tn.gov/tdot/topic/book-a-planner. Accessed Mar. 28, 2017.

43. Tennessee Department of Transportation staff. phone interview. Jan 31, 2017.

44. MIG. Evaluation of the Plan Bay Area Public Outreach and Participation Program. San Francisco, CA, 2013.

45. Singleton, Jr., R. A., and B. C. Straits. Approaches to Social Research. Oxford University Press, New York, 2005.

46. Bailey, K., and T. Grossardt. Toward Structured Public Involvement: Justice, Geography and Collaborative Geospatial/Geovisual Decision Support Systems. Annals of the Association of American Geographers, Vol. 100, No. 1, 2009, pp. 57-86.

47. Bickerstaff, K., and G. Walker. Shared visions, unholy alliances: Power, governance and deliberative processes in local transport planning. Urban Studies, Vol. 42, No. 12, 2005, pp. 2123-2144.

48. Gray, S., R. Milton, and A. Hudson-Smith. Advances in Crowdsourcing: Surveys, Social Media and Geospatial Analysis: Towards a Big Data Toolkit. In Advances in Crowdsourcing, Springer International Publishing, Cham, pp. 163-179. 